\title{
SỤ๋ CẦN THIẾT VÀ CƠ SỞ KHOA HỌC XÂY DỰNG CƠ SỞ DỬ LIỆU NHẠY CẢM MÔI TRƯỜNG TỔNG HợP TOÀN QUỐC
}

TS. NGUYẼ̃N DƯ KHANG

Cục Viễn thám quốc gia

\section{Tóm tắt:}

Tác động manh mẽ của thiên tai và biến đổi toàn cầu cùng những hệ lụy của quá trình phát triển kinh tế xã hội đã gây nên các hiểm họa môi trường đe dọa đời sống xã hội, tính mạng và tài sản của con người. Trong tình hình đó, nhu cầu thông tin về trạng thái môi trường là rất cần thiết để cung cấp cơ sở khoa học, hỗ trợ công tác quản lý về phòng tránh, ngăn ngừa và giảm thiểu tác động xấu của các hiểm họa môi trường. Để giải quyết những vấn đề đó, chỉ số nhạy cảm môi trường và chỉ số nhạy cảm môi trường tổng hợp là cơ sở để xây dựng hệ thống bản đồ nhạy cảm môi trường các tỷ lệ phù hợp với từng địa phương bằng công nghệ viễn thám và hệ thống thông tin địa lý GIS. Trong đó công nghệ viễn thám được áp dụng để xây dựng bộ bản đồ sinh thái ứng dụng từ tư liệu ảnh viễn thám. Công nghệ hệ thống thông tin địa lý (GIS) nhằm xây dựng các bộ bản đồ và cơ sở dữ liệu chuẩn về môi trường với sự tham gia của các chuyên gia môi trường, ap dụng phương pháp cây phân tích hệ thống AHP. Thành quả thu được là cơ sở dữ liệu nhạy cảm môi trường tổng hợp toàn quốc sẽ góp phần phục vụ công tác nhà nước về quản lý môi trường, giúp phòng tránh, ngăn ngừa và giảm thiểu tác động xấu của các hiểm họa môi trường, đảm bảo phát triển kinh tế, xã hội và môi trường theo hướng bền vững hơn trong tương lai.

\section{Sự cần thiết}

Mục đích của việc xây dựng cơ sở dữ liệu nhạy cảm môi trường toàn quốc là phục vụ phát triển bền vững kinh tế, xã hội và môi trường của nước ta. Hiện nay, vấn đề phát triển bền vững đã trở thành kim chỉ nam cho nhiều quốc gia không phân biệt mức độ phát triển. Phát triển bền vững có thể hiểu là "Cải thiện chất lượng sống của con người trong khi đang sống trong phạm vi khả năng cung cấp của các hệ sinh thái".

Bên cạnh tác động mạnh mẽ của thiên tai và biến đổi khí hậu toàn cầu, quá trình phát triển kinh tế xã hội kéo theo nhiều hệ luy đến môi trường sinh thái. Phải kể đến một số hiểm hoạ như: Động đất; Trượt lở đất đá, xói mòn; Lũ lụt, lũ quét; Hạn hán, thiếu nước; Ô nhiễm môi trường nước; Ô nhiễm môi trường đất; Ô nhiễm không khí; Ô nhiễm công nghiệp, hoá chất; Tràn dầu, Nguy cơ vỡ đê, kè, đập nước; Chặt phá rừng, cháy rừng; v.v.

Để có cơ sở khoa học giúp cho công tác quản lý nhà nước về phòng tránh, ngăn ngừa và giảm thiểu những tác động xấu của những hiểm hoạ trên đến đời sống xã hội, tính mạng và tài sản của con người, cũng như bảo đảm cho việc phát triển kinh tế, xã hội và môi trường bền vững, cần phải có những thông tin về trạng thái môi trường và diễn dịch chúng thành dạng dễ hiểu để thông tin cho các cấp lãnh đạo xem xét ra quyết định. Chỉ số nhạy cảm môi trường (sensitivity index) đối với một hợp phần môi trường và Chỉ số nhạy cảm môi trường tổng hợp (Synthesis sensitivity index) đối với đồng thời nhiều hợp phần môi trường tác động đến các yếu tố bị ảnh hưởng, là cơ sở thông tin để giải quyết những vấn đề nêu trên.

Cơ sở dữ liệu nhạy cảm môi trường tổng hợp toàn quốc được xây dựng trên cơ sở 
chuẩn hoá hệ thống bản đồ nhạy cảm môi trường với các tỷ lệ được thiết kế phù hợp với từng vùng, từng khu vực hoặc từng địa phương.

Hệ thống bản đồ nhạy cảm môi trường được xây dựng trên cơ sở bộ bản đồ nền chuyên đề có nội dung là các đơn vị sinh thái của các đối tượng tự nhiên và nhân tạo được biểu thị bằng các gam màu, dựa trên các thông tin thuộc tính thể hiện các mức của chỉ số nhạy cảm môi trường. Thông thường các mức nhạy cảm môi trường được chi thành 05 mức: nhạy cảm rất thấp, nhạy cảm thấp, nhạy cảm trung bình, nhạy cảm cao và nhạy cảm rất cao.

Xuất phát từ nhu cầu thực tế và khả năng giải quyết một cách khoa học những vấn đề bức xúc về môi trường hiện nay, việc xây dựng một cơ sở dữ liệu nhạy cảm môi trường tổng hợp cho toàn quốc là cần thiết.

\section{Giải pháp kỹ thuật và công nghệ}

Giải pháp kỹ thuật và công nghệ chủ yếu để việc xây dựng cơ sở dữ liệu nhạy cảm môi trường tổng hợp là công nghệ viễn thám và hệ thống thông tin địa lý (GIS).

\subsection{Công nghệ viễn thám}

Được áp dụng để xây dựng các bộ bản đồ sinh thái bằng tư liệu ảnh viễn thám, gồm công tác nội nghiệp và ngoại nghiệp.

\subsubsection{Công tác nội nghiệp:}

Thực hiện theo theo quy trình công nghệ thành lập bản đồ chuyên đề bằng công nghệ viễn thám với nội dung được phân thành các nhóm, các lớp và các đối tượng độc lập (các đơn vị đồng nhất về nhạy cảm môi trường) thuộc các lớp. Các đối tượng có thể là khoanh vi, dạng đường hoặc dạng điểm.

Đối với nội dung bản đồ chuyên đề sinh thái có thể phân loại như sau: (Xem bảng)

Dựa vào đặc điểm khu vực triển khai, có thể lược bỏ hoặc bổ sung thêm số nhóm và số lớp sinh thái của các nội dung trên.

\subsubsection{Công tác ngoại nghiệp:}

Bao gồm điều vẽ bổ sung ngoại nghiệp trong quy trình công nghệ thành lập bản đồ chuyên đề bằng công nghệ viễn thám, kết hợp công tác thu thập thông tin, tư liệu liên quan đến môi trường.

Thu thập thông tin, tư liệu bao gồm xác định các yếu tố môi trường thành phần đã xảy ra trong quá khứ, đang xảy ra trong hiện tại, hoặc có thể xảy ra trong tương lai ảnh hưởng đến các hệ sinh thái.

Các yếu tố môi trường thành phần bao gồm trong cả ba lĩnh vực chính của tự nhiên là môi trường không khí, môi trường đất và môi trường nước, ngoài ra, còn các hiểm hoạ môi trường khác do thiên tai, biến đổi khí hậu và ô nhiễm môi trường do con người gây ra cho các hệ sinh thái.

\section{2. Áp dụng công nghệ hệ thống thông tin địa lý (GIS)}

Nhằm xây dựng các bộ bản đồ và cơ sở dữ liệu chuẩn về nhạy cảm môi trường. Ở đây phát huy vai trò của các chuyên gia về môi trường và có các kiến thức tổng hợp khác. 


\section{Nghiên cúu - Úng dụng}

\begin{tabular}{|c|c|}
\hline $\mathbf{A}$ & Các hệ sinh thái trên môi trường đất \\
\hline$T$ & Nhóm sinh thái trồng cây hàng năm \\
\hline 1 & Lớp chuyên trồng lúa \\
\hline 2 & Trồng lúa - màu \\
\hline 3 & Trồng rau màu \\
\hline 4 & Trồng cây hàng năm khác \\
\hline II & Nhóm sinh thái trồng cây lâu năm \\
\hline 5 & Lớp cây công nghiệp \\
\hline 6 & Trồng cây ăn quả \\
\hline 7 & Trồng cây lâu năm khác \\
\hline III & Nhóm sinh thái rùng \\
\hline 8 & Lớp rừng tự nhiên \\
\hline 9 & Rừng sản xuất \\
\hline 10 & Khu bảo tồn động, thực vật \\
\hline 11 & Các loại rừng khác \\
\hline IV & Nhóm sinh thái nhân tạo \\
\hline 12 & Lớp đất ở nông thôn \\
\hline 13 & Đất ở đô thị \\
\hline 14 & Làng chài tập trung, bến cá \\
\hline 15 & Đất làm muối \\
\hline 16 & Đất trụ sở cơ quan, công trình sự nghiệp \\
\hline 17 & Đất khu công nghiệp \\
\hline 18 & Đất cho hoạt động khoáng sản \\
\hline 19 & Đất giao thông, sân bay, bến cảng \\
\hline 20 & Đất thủy lợi \\
\hline 21 & Đất công trình năng lượng \\
\hline 22 & Hệ sinh thái nhân tạo khác \\
\hline B & Các hệ sinh thái trên môi trường nước \\
\hline $\bar{V}$ & Nhóm sinh thái mặt nước \\
\hline 23 & Lớp mặt nước biển \\
\hline 24 & Lớp mặt nước biển \\
\hline 25 & Mặt nước chuyên dùng \\
\hline 26 & Đầm, phá ven biển \\
\hline 27 & Hệ sinh thái mặt nước khác \\
\hline VI & Nhóm sinh thái ngập mặn \\
\hline 28 & Lớp rừng ngập mặn \\
\hline 29 & Bãi san hô \\
\hline 30 & Bãi cói, cỏ nước, cây bụi ngập mặn \\
\hline 31 & Bãi sò, ron, rắt, nhuyễn thể \\
\hline 32 & Hệ sinh thái ngập mặn khác \\
\hline VII & Nhóm sinh thái nuôi trồng thuỷ sản \\
\hline 33 & Lớp nuôi trồng thủy sản nước lợ, mặn \\
\hline 34 & Lớp nuôi trồng thủy sản nước lợ, mặn \\
\hline 35 & Nuôi thủy sản lồng bè \\
\hline 36 & Nuôi trồng thuỷ sản khác \\
\hline
\end{tabular}


Sử dụng phương pháp cây phân tích hệ thống (AHP), có sơ đồ như hình 1.

Ở đây, $m$ là số hợp phần môi trường đưa vào đánh giá, $\mathrm{M}_{\mathrm{j}}$ là hợp phần môi trường thứ $\mathrm{j}(\mathrm{j}=1 \div \mathrm{m})$. Các hợp phần môi trường có thể là: Động đất; Trượt lở đất; Lũ lụt, lũ quét; Hạn hán, thiếu nước; Ô nhiễm môi trường nước; Ô nhiễm môi trường đất; Ô nhiễm không khí; Ô nhiễm công nghiệp, hoá chất; Ô nhiễm do khai thác, chế biến khoáng sản; Tràn dầu; Nước biển dâng; Nguy cơ vỡ đê, kè, đập nước; Chặt phá rừng, cháy rừng; v.v.

$\mathrm{n}$ là số nhóm sinh thái, $\mathrm{N}_{\mathrm{i}}$ là nhóm sinh thái thứ $\mathrm{i}(\mathrm{i}=1 \div \mathrm{n})$. Ví dụ: $\mathrm{N}_{1}$ là nhóm sinh thái cây trồng hàng năm.

Is(i) là số lớp sinh thái trong nhóm sinh thái $\mathrm{N}_{\mathrm{i}}(\mathrm{i}=1 \div \mathrm{n})$, $\mathrm{L}_{\mathrm{li}}$ là lớp sinh thái thứ I $(\mathrm{I}=1 \div$ Is(i)) trong nhóm sinh thái $N_{i}$. Ví dụ: $L_{11}$ là lớp sinh thái vùng chuyên trồng lúa trong nhóm sinh thái cây trồng hàng năm.

ks $(l, i)$ là số đơn vị sinh thái trong lớp sinh thái $\mathrm{L}_{\mathrm{li}}(\mathrm{I}=1 \div \mathrm{Is}(\mathrm{i}))$ của nhóm sinh thái $\mathrm{N}_{\mathrm{i}}(\mathrm{i}=1$ $\div \mathrm{n}), \mathrm{K}_{\mathrm{kli}}(\mathrm{k}=1 \div \mathrm{ks}(\mathrm{l}, \mathrm{i}))$ là đơn vị sinh thái thứ $\mathrm{k}$ trong lớp sinh thái $\mathrm{L}_{\mathrm{li}}$ của nhóm sinh thái $\mathrm{N}_{\mathrm{i}}$. Ví dụ: $\mathrm{K}_{111}$ là đơn vị thứ nhất trong lớp sinh thái vùng chuyên trồng lúa của nhóm sinh thái cây trồng hàng năm.

Kết quả thực hiện AHP có kiểm chứng bằng chỉ số nhất quán ngẫu nhiên, thu được: Trọng số $\mathrm{W}_{\mathrm{ij}}$ của nhóm sinh thái $\mathrm{N}_{\mathrm{i}}$ dưới tác động của hợp phần môi trường $\mathrm{M}_{\mathrm{j}}$; Trọng số $\mathrm{W}_{\mathrm{lij}}$ Của lớp sinh thái $\mathrm{L}_{\mathrm{li}}$ trong nhóm sinh thái $\mathrm{N}_{\mathrm{i}}$ dưới tác động của hợp phần môi trường $\mathrm{M}_{\mathrm{j}}$ và trọng số $\ddot{w}_{\mathrm{klij}}$ của đơn vị sinh thái $\mathrm{K}_{\mathrm{kli}}$ thuộc lớp sinh thái $\mathrm{L}_{\mathrm{li}}$ trong nhóm sinh thái $\mathrm{N}_{\mathrm{i}}$ dưới

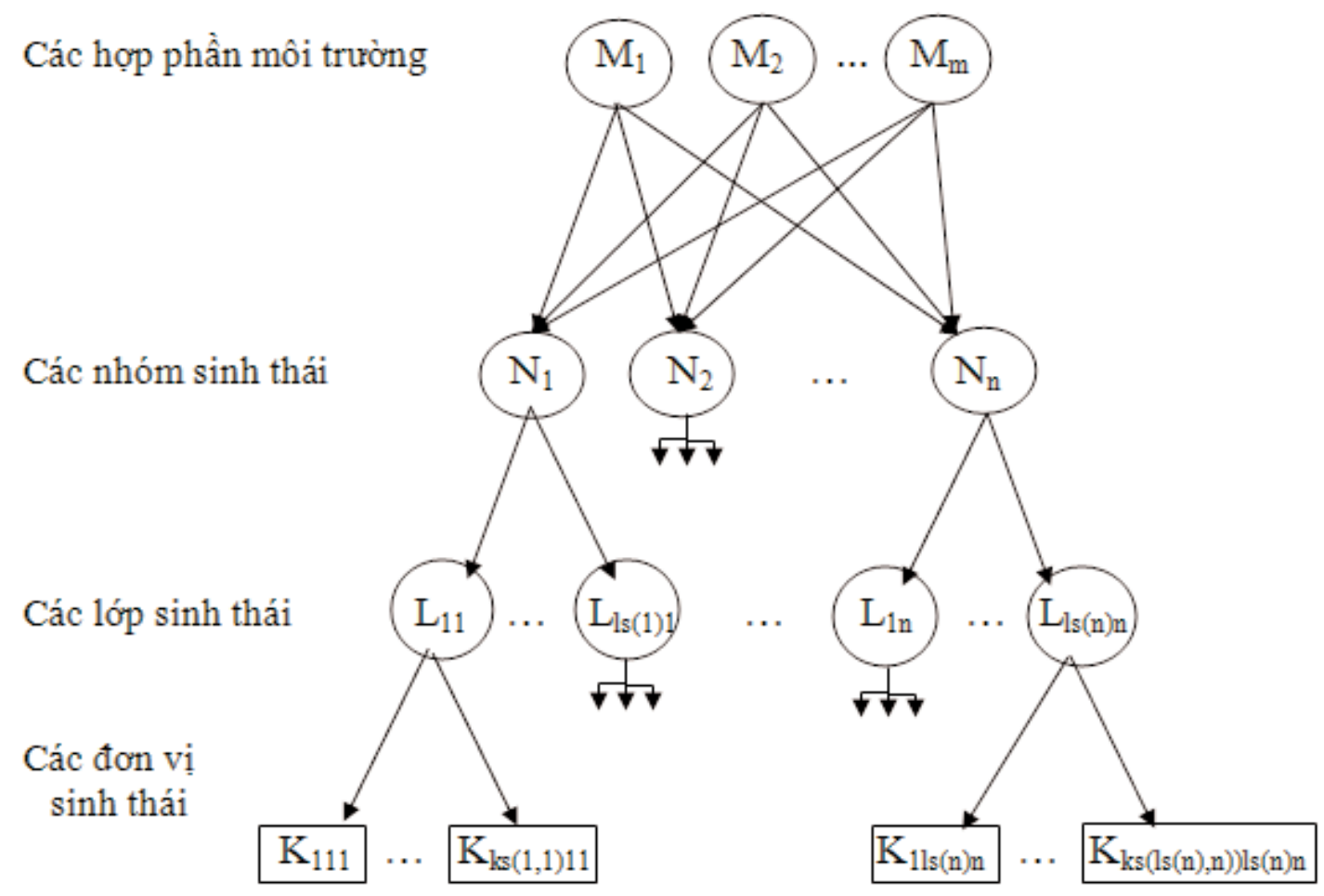

Hình 1: Phương pháp cây phân tích hệ thống (AHP) 
tác động của hợp phần môi trường $\mathrm{M}_{\mathrm{j}}$.

Tích hợp các số liệu, xác định chỉ số nhạy cảm môi trường $\mathrm{SI}_{\text {klij }}$ của các đơn vị sinh thái dưới tác động từng hợp phần môi trường theo công thức:

$$
S I_{\text {klij }}=S_{\text {klij }} \times h_{1}
$$

trong đó: $\quad S_{k l i j}=W_{\text {ij }} \times w_{l i j} \times \ddot{w}_{k l i j}$

$\mathrm{h}_{1}$ là hệ số, lựa chọn sao cho $\max \left(\mathrm{SI}_{\mathrm{klij}}\right)$ có giá trị bằng 9 .

Chỉ số nhạy cảm môi trường tổng hợp của các đơn vị sinh thái dưới tác động đồng thời của các hợp phần môi trường xác định theo công thức:

$$
\mathrm{SSI}_{\mathrm{kli}}=\mathrm{SS}_{\mathrm{kli}} \times \mathrm{h}_{2}
$$

trong đó:

$$
\mathrm{SS}_{\mathrm{kli}}=\sum_{\mathrm{J}=1}^{\mathrm{m}} \mathrm{S}_{\mathrm{klij}}
$$

$\mathrm{h}_{2}$ là hệ số, lựa chọn sao cho max $\left(\mathrm{SSI}_{\mathrm{ilk}}\right)$ có giá trị bằng 9 .

Thang phân cấp chỉ số nhạy cảm môi trường và nhạy cảm môi trường tổng hợp của các đơn vị sinh thái được chia thành 5 cấp:

Cấp 1: $0 \leq \mathrm{SI}$ (hoặc SSI) $<1$ :

Nhạy cảm rất thấp

Cấp 2: $1 \leq \mathrm{SI}$ (hoặc SSI) < 3:

Nhạy cảm thấp

Cấp 3: $3 \leq \mathrm{SI}$ (hoặc SSI) < 5:

Nhạy cảm trung bình

Cấp 4: $5 \leq \mathrm{SI}$ (hoặc SSI) < 7:

Nhạy cảm cao

Cấp 5: $7 \leq \mathrm{SI}$ (hoặc SSI) $\leq$ 9:

Nhạy cảm rất cao.

Nhập giá trị chỉ số nhạy cảm các môi trường tổng hợp của các đơn vị sinh thái vào bản đồ sinh thái ứng dụng. Biểu thị các gam màu (theo mức độ nhạy cảm môi trường) và biên tập bản đồ chuyên đề. Chuẩn hoá hệ thống bản đồ chuyên đề theo quy định hiện hành, sản phẩm là một cơ sở dữ liệu nhạy cảm môi trường tổng hợp.

\section{Hiệu quả kinh tế - xã hội và môi trường}

Cơ sở dữ liệu nhạy cảm môi trường tổng hợp, kể cả nhạy cảm của từng hợp phần môi trường, có những chức năng cơ bản như:

Hiệu quả thông tin: Cho một cái nhìn tổng quan về môi trường, giảm số lượng các đo lường và các thông số để trình bày hiện trạng môi trường; 
Đơn giản hóa thông tin: Làm đơn giản hóa quá trình giao tiếp thông tin và thông qua chúng, các kết quả đo lường được cung cấp cho người sử dụng;

Phòng ngừa: Tóm lược hiện trạng môi trường hiện tại, làm gia tăng sự quan tâm của lãnh đạo đối với môi trường nhằm phòng ngừa sự thay đổi các tình trạng môi trường;

Quyết định: Thay đổi hành vi, định hướng hành động, tập trung vào sự phát triển bền vững hơn là vào tăng trưởng kinh tế thuần túy, từ đó hoạch định một môi trường bền vững trong tương lai.

Với những chức năng như trên. cơ sở dữ liệu nhạy cảm môi trường tổng hợp toàn quốc góp phần phục vụ công tác quản lý nhà nước về môi trường, giúp cho việc phòng tránh, ngăn ngừa và giảm thiểu những tác động xấu của các yếu tố môi trường do thiên tai, biến đổi khí hậu và do tác nhân con người gây ra, ảnh hưởng đến đời sống xã hội, tính mạng và tài sản của con người, cũng như bảo đảm cho việc phát triển bền vững kinh tế, xã hội và môi trường ở nước ta. $O$

\section{Tài liệu tham khảo}

[1]. John R. Jensen, Elijah W. Ramsey, Joseph M. Holmes, Jacquelin E. Michel, Basil Savitsky \& Bruce A. Davis, 1990. Environmental sensitivity index mapping for oil spills using remote sensing and geographic information system technology. International journal of geographical information systems, V.4.

[2]. Nguyễn Đình Mạnh, 2005. Giáo trình Đánh giá tác động môi trường.

[3]. Nguyễn Ngọc Thạch, Dương Văn Khảm, 2012. Địa thông tin ứng dụng (Các ứng dụng của Viễn thám, Hệ thông tin Địa lý và GPS). NXB Khoa học và Kỹ thuật.O

\section{Summary}

\section{The necessary and scientific basis for build database sensitive environments nationwide general}

\section{Dr. Nguyen Du Khang, National Remote Sensing Department}

Strong impact of natural disasters and global change as well as the consequences of unsustainable economic and social development caused environmental hazards threatening lives and properties of people. In that situation, the demand for information about the state of the environment is essential to provide a scientific basis to support the management in prevention and mitigation adverse impacts of environmental hazards. To solve these problems, environmental sensitivity index and total environmental sensitive index was a base for building the map systems of environmental sensitivity consistently with remote sensing and geographic information system (GIS). In which, remote sensing technology was used to establish eco-map applications from remote sensing imagery. Geographic Information System (GIS) technology was used to create standard maps and database of environment al issues with the participation of environmental experts, applying AHP analysis method. The obtained national environmental sensitive database will support the government in environmental management, help preventing and mitigating adverse impacts of environmental hazards ensuring economic, social and environment development towards a more sustainable future. $O$

Ngày nhận bài: 23/02/2015. 